\title{
Raman Microspectroscopy of Fixed Rabbit and Human Lenses and Lens Slices: New Potentialities
}

\author{
Axxet (.C. Bot*i, Alex Huizingat. Frits F. M. De Mult, \\ GLJS F. J. M. VRENSENt* AND JAN GREVE† \\ * Netherlands Ophthalmic Research Institute, P.O. Box 12141. 1100 AC Amsterdam. \\ The Votherlands. and + Tuente L'niversity of Technology. Faculty of Applied Physics. \\ P.O. Box 21\%. ז500 AE Enschede. The Nelherlards
}

(Rereired + March 1988 and accepted in rerised form 27 February 1989)

\begin{abstract}
Raman spectroscopy is a non-invasive, non-destructive technique for the study of the maxmolerulitr composition of tissues. Raman spectra were obtained from intact fresh and paraformaldehyde fixed rabbit lenses and from thin slices prepared from these lenses. In addition the Raman spectrum of an intact 82 -yr-old human lens was compared with a slice of the same lens. It appeared that fixation with paraformaldehyde had only a minor qualitative effect on the Raman spectra and that Raman spectra of intact lenses and lens slices were comparable. It was alwo shown that in the slice of the old human lens the fluorestence, due to rhromophores. could be reduced so that a reliable Raman spectrum could be obtained.

The use of slices improves the accuracy of the position at which Raman spectra are recorded and fixation extends the time available for Raman analysis which is particularly important for the st udy of human lenses. Moreover. slicing enables Ruman analysis of old human lenses. which up to now was thought to be impossible due to the overwhelming Huorescence of the (hromophores present in these lenses.

ke? words: Raman spestroseopy: owular lens: human: rabbit ageing: water content.
\end{abstract}

\section{Introduction}

Nenile cataract is still a major cause of blindness and several mechanisms have been proposed regarding its aetiology (Horkwin, 1985; Spector, 1984). Transmission and scanning electron microscopic studies have shown that early age dependent opacities remain restricted to small parts of individual fibres. These early opacities are found mainly in the equatorial superticial cortex of the lens (Harding et al., 1985). It has not yet been proved that these turbid spots precede mature senile cataract. Raman microspectroscopy is a non-destructive technique that enables the study of the macromolecular composition of small volumes ( $Y$ u. De Nagel. Pruett and Kuck, 1985b: Itoh, Ozaki, Mizuno and Iriyama, 1983: Yu and East, 1975; Ozaki et al.. 1983). It is stated that a useful Raman spectrum can be recorded from a volume of $10^{-3} \mu \mathrm{l}$ (Yu et al.. 1985b), and therefore it seems to be a useful method to investigate macromolecular alterations in opaque sataractous spots. It is also considered to be a promising clinical diagnostic tool for senile cataract ( $\mathrm{Yu}$. Kuck and Askren. 1981-2: Mathies and Y u, 1978; Mizuno et al., 1981-2).

It is suggested that especially the water band $\left(3390 \mathrm{~cm}^{-1}\right)$ is useful as a clinical diagnostic marker of early cataractous signs in vivo (Iriyama. Mizuno, Ozaki, Itoh and Matzuzaki, 1982 3). Many cataracts show a change in the balance of water influx and efflux. This is supported by investigations on the process of syneresis during (ataract formation (Bettelheim, Ali. White and Chylack, 1986a; Bettelheim, Castoro, White and ('hylack. 1986b). As the $3390 \mathrm{~cm}^{-1}$ band has a very strong intensity it can

+ To whom all reprint requests should be addressed. 
be detected using low laser power. and consequently radiation damage will be low or absent. It has been possible to measure the Raman spectrum of a bovine lens with only $1 \mathrm{~mW}$ of laser power with about 700 to $950 \mathrm{sec}$ data integration time (Mathies and Yu, 1978).

Raman spectra of intart human lenses have been recorded by several investigators (Gijsbers et al., 1986; Kuck and Yu, 1978; Yu, Kurk and Askren, 1979: Yu, Bando and Kuck, 1985a). They were confronted with the following problems: (i) excessive fluorescence in human lenses above the age of $20 \mathrm{yr}$ ( $\mathrm{Kuck}$ and $\mathrm{Yu}, 1978$; Yu et al. 1979; Yu et al., 1985a), (ii) difficulty regarding the precise focusing on opaque and translucent regions, and (iii) limited availability of fresh human lenses.

The aim of the present study was to improve the accuracy in position of the measurement of Raman spectra by using lens slices. In order to prepare lens slices, the lenses have to be fixed otherwise they are too soft to be cut. Fixation will also increase the time available for Raman study, which is especially advantageous for human lenses. In addition it would allow ultrastructural investigations of the Raman recorded regions. Paraformaldehyde was chosen as the fixative because in a previous study (Gijsbers et al., 1986) this fixating solution proved to have very little effect on the Raman spectra of lenses and even after 16 days of fixation no changes in the ultrastructure of the lens were observed. Paraformaldehyde did not influence the clarity of lenses. Glutaraldehyde proved not to be useful for these studies because it caused severe fluorescence. As the parameter to prove the usefulness of the present method the water:protein ratio indicated by the ratio of the intensity of the water band at $3390 \mathrm{~cm}^{-1}$ (which is due to the $\mathrm{OH}$ stretching mode) and the intensity of the protein band at $2935 \mathrm{~cm}^{-1}$ (due to aliphatic $\mathrm{CH}$ stretching vibration) was used.

To our knowledge no reports exist on the recording of Raman spectra of lens slices. In this study Raman spectra of intact rabbit lenscs were compared with spectra of thin slices of about $1 \mathrm{~mm}$ of the same lenses. The spectrum of an 82 -yr-old human lens was also compared with the spectrum of a slice of the same lens.

\section{Materials and Methods}

The Raman spectra were recorded with a system consisting of a SPEX 1877B spectrometer, an EG\&G PAR OMA III multichannel analyzer with an intensified 1024 diode array model 1421, an Olympus BSM metal microscope, and a Coherent model 52 Argon-ion laser with Innova tube emitting at $514.5 \mathrm{~nm}$. The required coupling opties were developed in our laboratory (Gijsbers et al., 1986).

The laser beam is directed into the microscope objective via a beamsplitter and a $90^{\circ}$ prism. To view the laser spot in the sample the strongly reduced laser beam is reflected by a beam splitter cube, which allows light from the sample to reach the binocular or a colour video camera. The Raman backscattered light is collected by the microscope objective and is focused on the entrance slit of the spectrograph by a $f=40 \mathrm{~mm}$ achromatic lens (Gijsbers et al., 1986). The effective entrance pupil in the plane of the entrance slit is $100 \times 1500 \mu \mathrm{m}$. Laser power at the sample is $25 \mathrm{~mW}$, resolution $4 \mathrm{~cm}^{-1}$. To measure Raman spectra of the intact rabbit lenses both the lens and the $20 \times$ objective were immersed in phosphate buffered saline (PBS), whereas using the $50 \times$ objective only the lens and not the objective was immersed. The $50 \times$ objective was used for the rabbit lens slices. For both the intact human lens and its slices the $20 \times$ objective was used. The effective sample volume is defined by the dimensions of the entrance pupil of the spectrometer and the waist diameter of the laser beam. Waist diameter. focal depth and measured volume for the $20 \times$ objective and the $50 \times$ objective are $5 \mu \mathrm{m}, 10 \mathrm{~mm}, 170 \times 10^{-3} \mu \mathrm{l}$ and $2 \mu \mathrm{m}, 0.1 \mathrm{~mm}, 3 \times 10^{-3} \mu \mathrm{l}$ respectively.

The animal lenses used in this study were extracted from healthy Dutch belted rabbits (18 

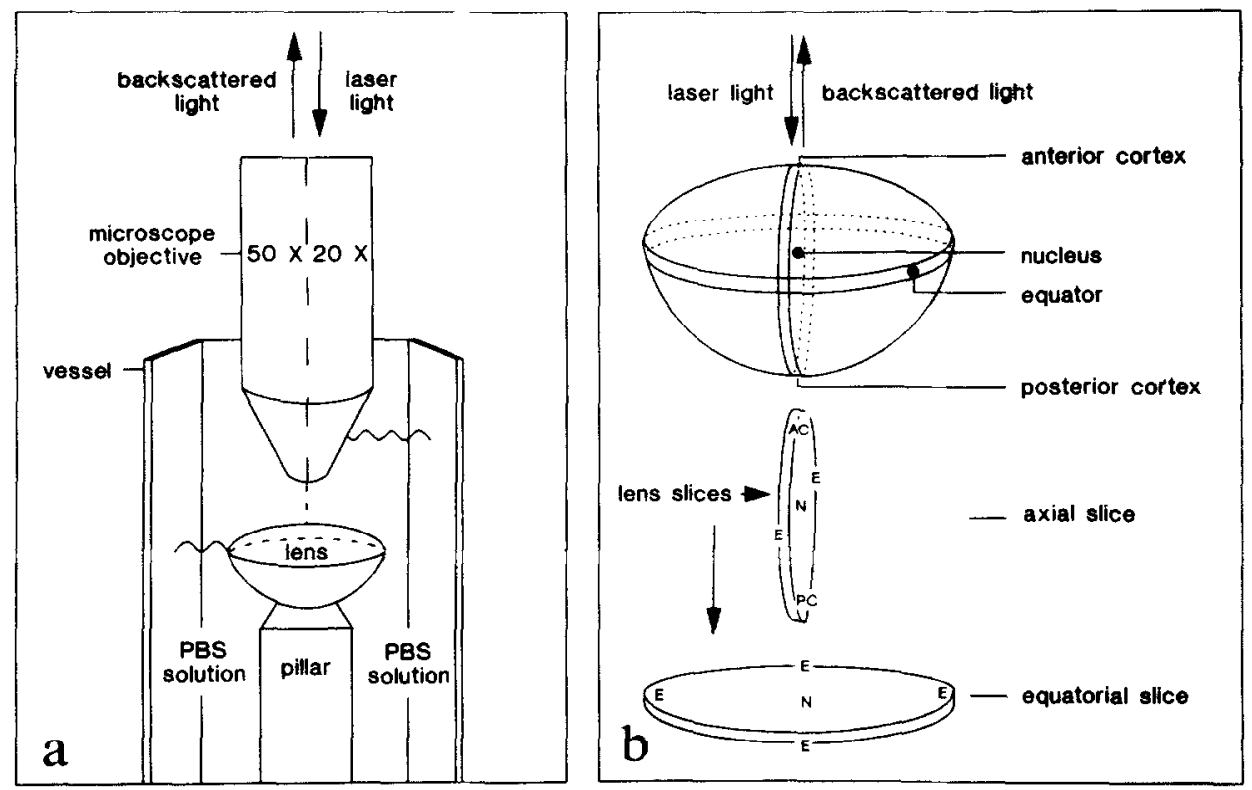

Fig. 1(a) Schematic drawing of the sample arrangement for Raman analysis of the intact lenses. The $50 \times$ objective was not immersed in the phosphate buffered saline (PBS) solution to avoid contribution of PBS in the Raman spectra when measuring at the lens surface. The $20 \times$ objective was used for measurements deeper in the lens and was immersed in PBS to gain focal depth. (b) Raman analysis was rarried out along the visual axis by focusing the laser waist as indicated in this figure. Lens slices were cut along the visual axis (rabbit) or in the equatorial plane (human lens).

months old). Four clear fresh lenses were used without any treatment within $5 \mathrm{hr}$ after death. Six lenses were fixed for several weeks at $4^{\circ} \mathrm{C}$ in a solution consisting of $0.08 \mathrm{M}$ cacodylate buffered $1 \%$ paraformaldehyde, $\mathrm{pH} \mathrm{73}$. Both the fresh and fixed lenses were positioned on a pillar in a small vessel containing a phosphate buffered salt solution (PBS) (Fig. 1). The excess PBS dilutes the unbound paraformaldehyde and cacodylate in the fixed lenses by a factor of at least $100(40 \mathrm{ml} P B S$ and $450 \mathrm{mg}$ lens wet weight). Lsing the vertical focusing adjustment of the specimen stage the laser waist was focused on different positions in the lens. With the $50 \times$ objective spectra were recorded along the visual axis from the surface until $0.5 \mathrm{~mm}$ under the surface with steps of $0.1 \mathrm{~mm}$. Subsequently, using the $20 \times$ objective, measurements were carried out from $1 \mathrm{~mm}$ below the surface to the nucleus with steps of $1 \mathrm{~mm}$. The same procedure was used after turning the lens upside down. For each position four spectral regions were recorded: $300-1450 \mathrm{~cm}^{-1}, 750-1850 \mathrm{~cm}^{-1}, 2450-3400 \mathrm{~cm}^{-1}, 3000-$ $4100 \mathrm{~cm}^{-1}$. In the figures the four spectral regions are condensed to two: $300-1700 \mathrm{~cm}^{-1}$ and $2500-3900 \mathrm{~cm}^{-1}$. The pixel numbers of the multichannel detector were calibrated in $\mathrm{cm}^{-1}$ with an Argon-calibration lamp, using a cubic fit procedure. The sensitivity variation over the multichannel detector range was eliminated by using a correction curve for each spectral region.

After measuring the fixed intact lenses, slices of about $1 \mathrm{~mm}$ were cut along the visual axis with a razor blade. The slices were put on a glass slide and PBS was used to prevent drying. Finally they were covered with a coverglass of $0.17 \mathrm{~mm}$ thickness. Raman spectra were recorded at different positions using the horizontal stage controls. The Raman instrumental conditions were the same as for the intact lenses except that a $50 \times$ objective was used throughout. All spectra were obtained at ambient temperature.

The relative water:protein content in each region was calculated using

$$
\text { the ratio } \rho=\frac{\text { (intensity } 3390-\text { intensity background) }}{\text { (intensity } 2935 \text { - intensity barkground) }} \text {. }
$$



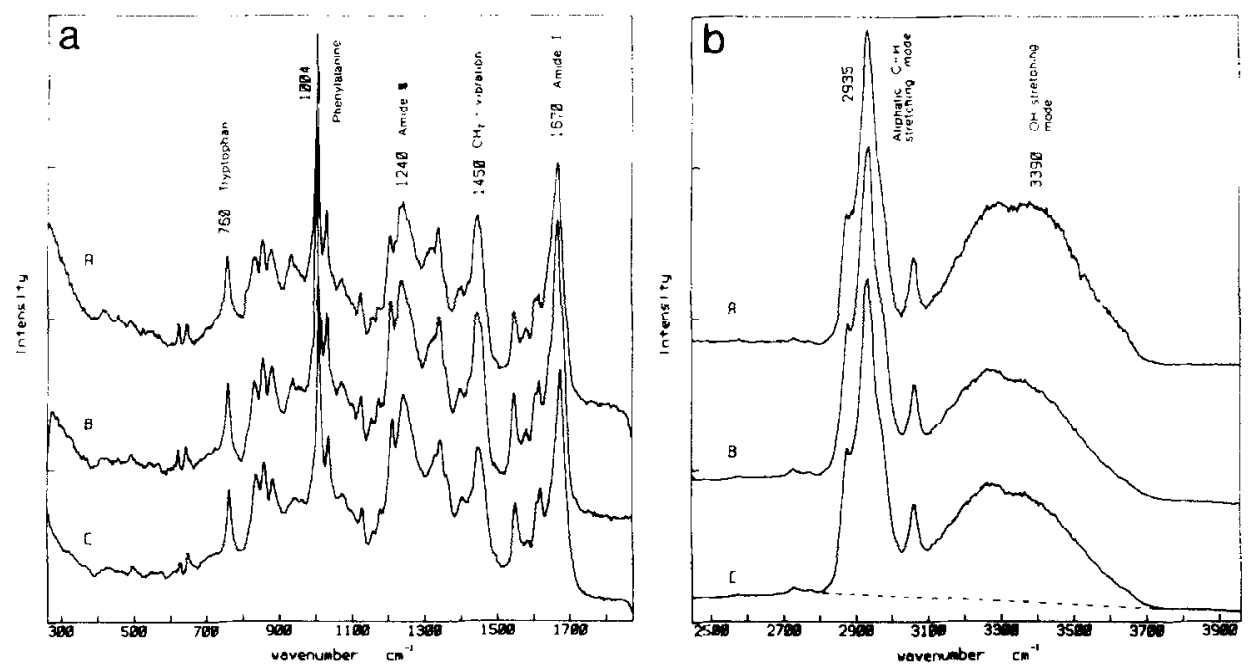

FIG. 2. Example of Raman spectra of one rabbit lens ; intact fresh (A), intact paraformaldehyde-fixed (B) fixed and sliced (C) for two different spectral regions : $300-1700 \mathrm{~cm}^{-1}$ (a) and $2500-3900 \mathrm{~cm}^{-1}$ (b). The spectra were recorded in the nuclear region. Instrumental conditions: laser power at sample $\mathbf{2 5} \mathrm{mW}$, excitation wavelength $514.5 \mathrm{~nm}$, resolution $4 \mathrm{~cm}^{-1}$ (slit width $100 \mathrm{\mu m}$ ), total data integration time 240 sec. N.B. For convenience the spectra have been plotted on top of each other. The intensities of the three spectra were comparable. As the assignment of all the different peaks is not of great importance for the present paper the reader is referred to Gijsbers et al. (1986) and Yu et al. (1981) for further details.

The background is estimated to be according to the dashed line as indicated in Fig. 2 (b). It is not necessary to use the integrated Raman band areas, because it can be assumed that the width of the bands is constant. So for relative intensities only the height of the band is important. To correlate the ratio to the absolute mass percentage of water. it is necessary to carry out a calibration procedure.

Using the same procedure we also studied an 82-yr-old brunescent. but non-turbid, human lens with small opaque spots. In order to erase the excessive fluorescence (Gijsbers et al.. 1986; Yu et al., 1985a) a clear region in the intact lens was irradiated with laser light for $8 \mathrm{hr}$ before recording a spectrum. After recording a slice was cut parallel to the equatorial axis. as the opaque spots were in this region. A clear spot in the equatorial cortex of the slice was irradiated with laserlight for $2-18 \mathrm{hr}$ before the actual recording of the Raman spectra.

To check for a possible contribution of the fixative to the Raman spectra of the lenses. this solution was measured separately in a small vessel.

\section{Results}

Figure 2(a) and (b) exemplifies the Raman spectra obtained from one rabbit lens: fresh intact (A), fixed intact (B) and fixed and sliced (C). The spectra were all taken in the nuclear region. It proved that the spectra are reproducible from one lens to the other. In the intact lenses the absolute Raman intensity, over the whole spectrum, in the nuclear region was found to be lower than in the anterior and posterior eortex. This difference in intensity was absent in the lens slices.

Figure 3(a) and (b) illustrates the Raman spectrum of the fixating solution. The peak at $608 \mathrm{~cm}^{-1}$ is due to cacodylate, whereas the other peaks can be assigned to paraformaldehyde. Comparison of the spectra of Fig. 2 with the spectrum of Fig. 3 reveals that none of the cacodylate and paraformaldehyde peaks is found in the lens spectra. 

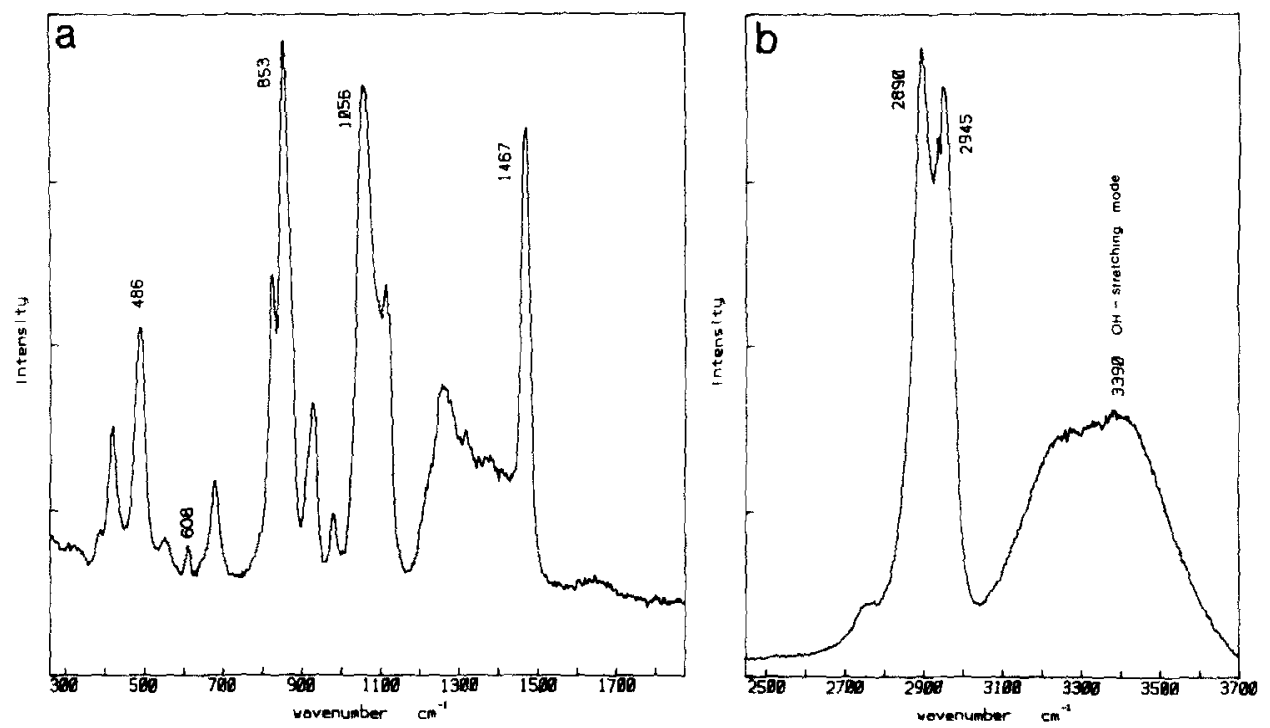

FiG. 3. Raman spectrum of the $0.08 \mathrm{~m}$ cacodylate buffered $1 \%$ paraformaldehyde fixating solution, pH 73 for two different spectral regions: $300-1700 \mathrm{~cm}^{-1}$ (a) and $2500-3700 \mathrm{~cm}^{-1}$ (b). Instrumental (onditions as in Fig. 2 except for the integration time which was $60 \mathrm{sec}$. The peak at $608 \mathrm{~cm}^{-1}$ is from cacodylate the others are from paraformaldehyde.

The relative water: protein content, indicated by the ratio $\left(\mathrm{I}_{3990}: \mathrm{I}_{2935}\right)$, throughout the lens is summarized in Fig. 4 for a fresh lens $(+)$, an intact fixed lens $(\square)$ and a fixed lens slice (1). A dramatic and rapid drop in the ratio from the cortex to the nucleus can be seen. Besides a difference in the anterior cortex the curves are identical for the fresh and fixed intact lens and the lens slice.

In accordance with the observations given in literature (cf. Yu et al., 1985a) no relevant Raman spectrum could be obtained from the intact old human lens. The fluorescence signal completely exceeded the Raman signal. Irradiation of the intact lens for $8 \mathrm{hr}$ did not significantly improve the Raman to fluorescent signal ratio. However, as illustrated in Fig. 5(a) and (b), $18 \mathrm{hr}$ irradiation of slices prepared from this lens results in a fluorescent free Raman signal for all wave numbers. In the region over $2500 \mathrm{~cm}^{-1}$ even $2 \mathrm{hr}$ or less of laser irradiation is sufficient to obtain a qualitative and quantitative reliable spectrum. In the cortex the ratio was about 1 indicating that the water : protein ratio is comparable to that of rabbits in this region (of. Fig. 4).

\section{Discussion}

The present study reveals that the Raman microspectroscopic set-up used in this and a previous study (Gijsbers et al., 1986) is reliable and sensitive. The Raman spectrum of a fresh intact rabbit lens [Fig. $2(A)]$ is qualitatively fully comparable with Raman spectra of mammalian lenses obtained with conventional macro-Raman devices ( $Y$ u et al., 1985b; Itoh et al., 1983: Yu and East. 1975; Ozaki et al., 1983; Yu et al., 1981-2). The microspectroscopic set-up has several advantages, the most important of which are: (i) due to the sharp focus lower laser energies can be used, (ii) the high numerical aperture of the objectives ensures an efficient collection of seattered light. (iii) the use of the specimen stage of the microscope enables precise 


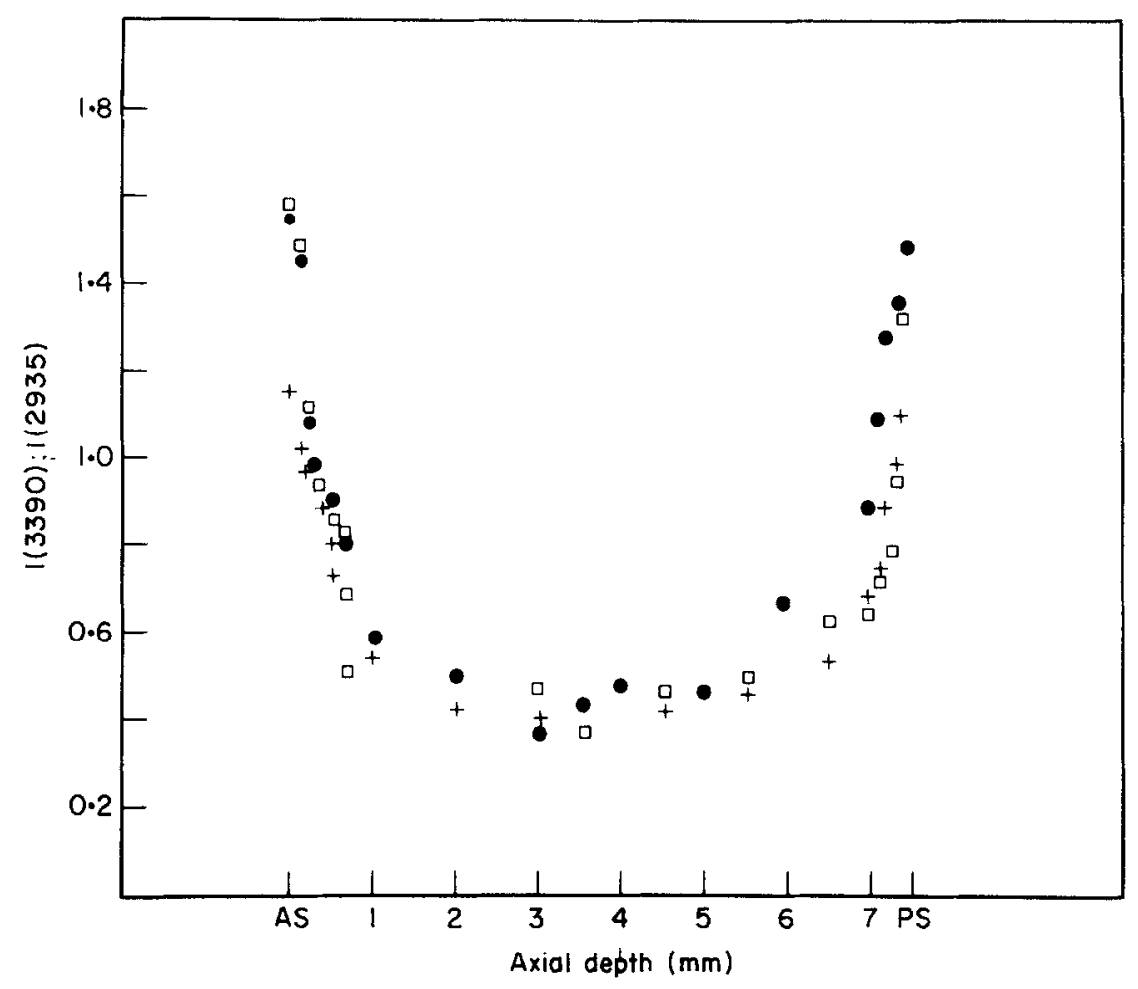

Fig. 4. The relative water to protein content of rabbit lenses throughout the whole axial depth. $(+)$ intact fresh lenses (four), ( $\square$ ) the same lenses fixed in paraformaldehyde and (O) axial lens slices prepared from the fixed lens.

$$
\rho=\frac{\text { intensity at } 3390 \mathrm{~cm}^{-1}(\mathrm{OH} \text {-band }) \text {-intensity background }}{\text { intensity at } 2935 \mathrm{~cm}^{-1}\left(\mathrm{C}^{-} \mathrm{H} \text { stretch }\right) \text {-intensity background }} .
$$

Note that the water to protein content is largely comparable for fresh and fixed intact lenses and lens slices pxcept for the most extreme anterior cortex. AS, anterior surfare: PS. [nsterior surfarte

and reproducible position-defined measurements, (iv) sample volume can be reduced to about $1 \mu \mathrm{m}^{3}$, and $(v)$ the contribution of sample material or solution, outside the waist of the laser beam, to the spectrum is negligible.

As indicated by the Raman spectra A, B and C of Fig. 2, the fixation of rabbit lenses with a cacodylate buffered paraformaldehyde solution does not influence the Raman spectrum. No additional peaks appear and no drop in sensitivity was observed. The relative intensities of the protein lines-- (e.g. tyrosyl stretching region at $825-855 \mathrm{~cm}^{-1}$ the $\mathrm{C}-\mathrm{C}$ and $\mathrm{C}-\mathrm{N}$ stretehing at $920-1050 \mathrm{~cm}^{-1}$, the amide III region at about 1240 $\mathrm{cm}{ }^{1}$ and the amide I region at about $1670 \mathrm{~cm}^{-1}$, the tryptophan line at $760 \mathrm{~cm}^{-1}$. and the phenylalanine peak at $1004 \mathrm{~cm}^{-1}$ )-have not changed within the limits of error. None of the Raman peaks recorded for the fixation solution was seen in the Raman spectra of the lenses, not even shoulders in the existing peaks. So we may assume that due to the replacement of the fixation solution by PBS the concentration of cacodylate and paraformaldehyde has become so low that it no longer contributes to the lens spectrum. It is unlikely that the buffer solution contributes to the spectra as such because the strong sodium phosphate peak commonly observed in the region of $950 \mathrm{~cm}^{-1}\left( \pm 25 \mathrm{~cm}^{-1}\right)$ is not observed at all. Moreover the PBS surrounding the lens 

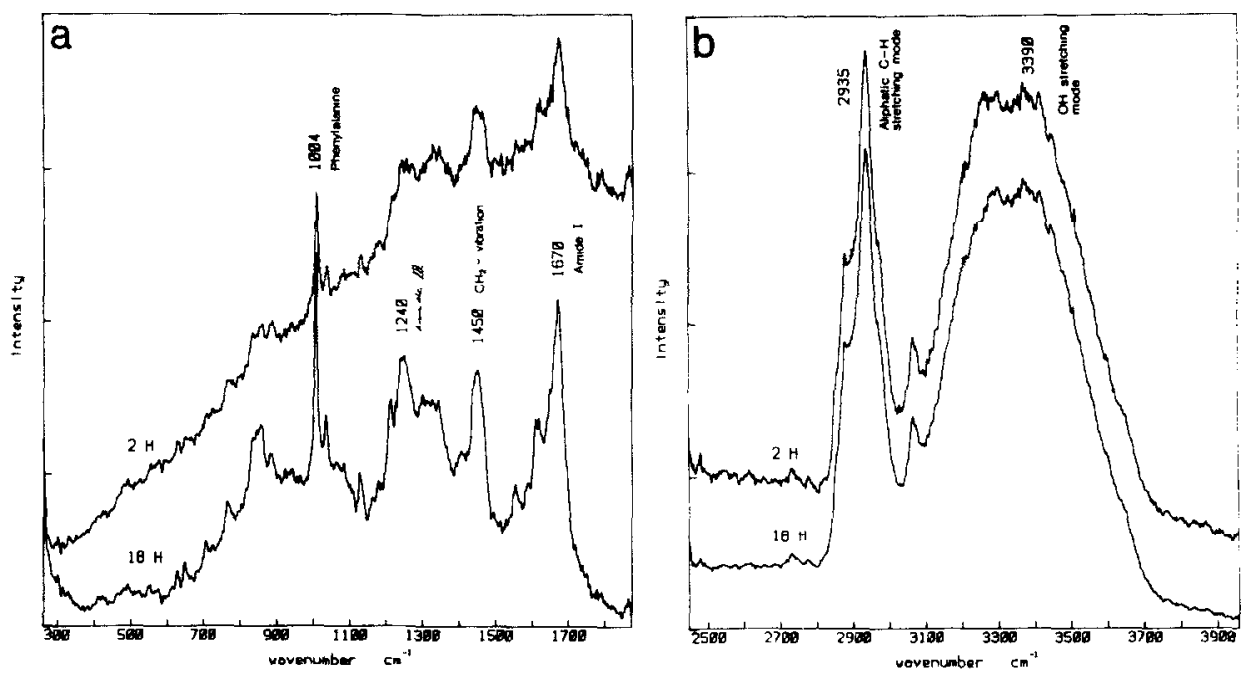

FIG. 5. Raman spectra of slices prepared of a fixed 82 -yr-old human lens 2 and 18 hr after laser preirradiation for two different spectral regions : $300-1700 \mathrm{~cm}^{-1}$ (a) and $2500-3900 \mathrm{~cm}^{-1}$ (b). The spectra are taken in the equatorial cortex. Instrumental conditions as in Fig. 2 except for the integration time which was $1200 \mathrm{sec}$.

does not contribute to the spectrum as at this place the laser beam is not focused and is not properly imaged in the entrance slit of the spectrometer. Finally, we have proved (Huizinga, Bot, De Mul, Vrensen and Greve, 1989) that the water content of lenses stored in PBS, either fixed or unfixed, is fully comparable with that measured with a number of other methods.

This unexpected observation has two important consequences: (i) it is no longer necessary to analyze the lenses directly after extraction. This is especially relevant for human lenses which are not always available at the exact time of the experiments. (ii) We have previously shown that paraformaldehyde fixation is adequate for fine structural investigation of the lens (Gijsbers et al., 1986). This means that Raman analysis can be combined with scanning and transmission electron microscopy of the same area.

The comparison of spectra B and C of Fig. 2 further reveals that slicing of the lens does not affect the Raman signals. This is further substantiated by the water : protein ratios summarized in Fig. 4 which, with minor differences, are comparable for identical regions in intact and sliced lenses. This situation has some obvious advantages : position-defined Raman analysis is much easier and more reproducible to perform in slices than in intact lenses especially in conjunction with a well calibrated specimen stage of the microscope. In addition, the decrease in Raman sensitivity from cortex to nucleus can be explained by the absorption of the incoming laser light and the backscattered Raman light above the focused position. This is supported by the observation that the intensity difference between cortex and nucleus is absent in slices. This latter is especially relevant for investigations in which comparisons between different lenticular regions are studied. Finally, we were unable to record Raman spectra from the equatorial region of intact lenses due to deflection of the laserbeam on the curved surface in this region. In lens slices this is no problem at all.

As outlined in the introduction, Raman microspectroscopy as a method for nondestructive, position-defined analysis of the macromolecular composition of tissues is 
of special interest for the study of lowal opacities in ageing human lenses. Howerer. as indjoated by numerous investigators (of. Yu et al. 19xina) Raman signals of human Ienses over the age of 20 30 $5 \mathrm{rr}$ are fully overwhelmed he the thenesent signals in these lenses. This frustrates one of the main objectives of Raman andysis in lems research. The present paper shows, however. that lens slices even of very old human lenses give reliable Raman spertrat. provided they are pre-irradiated with lasel light for several hours. The Raman spectra thus obtained are qualitatively fully comparahle to those obtained from young non-fluorescent human lenses (Kuck and Yw, 1978: Yu et al. 1985a). A main factor involved in the lower Huorescence of slices is that in a sice less fluorescent material is excited and that consequently also the backscattering of Huorescent light from positions outside the measured colume into the objertive will be less. In addition the absorption of Raman and laser light above the focused spot will be less in a slice. A point of concern is of course the effert of the pre-irradiation on the lens proteins. We must assume that pre-irradiation affects the ehromophores and their fluorescence and possibly the proteins as well. However. the good comparability of Raman spectra of the old human lens of the present study and young human lenses (Kuck and Yu. 1978: Yu et al.. 1985a) farours the riew that preirradiation does not affert the molecular strueture of the lens proteins but climinates only the fluorescence of the chromophores. The apparent difference in reaction on laser irradiation between chromophores and proteins is possibly due to the fact that chromophores absorb laser light and proteins do not absorb at the wavelength used and that consequently the chromophores are more likely to be destroyed by the laser light.

\section{A('KNOWLEDGMENTS}

The authors thank Mr B. Willekens for providing the rabbit lenses. We thank Eurotransplant. Leiden (The Netherlands) for making available the human lens for the present study and we are indebted to Dr E. Pels for collecting this lens. We thank $\mathrm{Vr} \mathrm{X}$. Bakker for adapting the figures and Mrs H. Fopma-Bonnes for typing the manuscript. This study was carried out within the framework of the European Economic Community' Concerted Action on Cellular Aging and Diseases. 'Eurage'. and was supported by the Netherlands Technology Foundation (STW).

\section{REFERENC'ES}

Bettelheim, F. A., Ali, A.. White. O. and (hylack. L. T. (1986a). Freezable and non-freezable water content of cataractous human lenses. Ineest. Ophthalmol. Fis. Sci. 27. 122.5.

Bettelheim, F. A. Castoro, J. A., White, P. and Chylack. L. T. (1986b). Topographir correspondence between total and non-freezable water content and the appearance of cataract in human lenses. Curr. Eye Res. 5. 925-32.

Gijsbers. G., Vrensen, G. Willekens. B.. Maatman. D.. De Mul. F. and Greve. J. (1986) Raman microspectroseopic investigations of human eve lenses. In Laser sirattering Spectroscopy of Biological Objects. (Eds Stepanek, J., Anzenbacher. P. and Sedlacek. B.). Pp. 583-94. Elsevier: Amsterdam.

Harding. C. V., Susan, S. R., Lo, W.-K., Bobrowski, F. R., Maisel. H. and ('hylack. L. T. (1985). The structure of the human cataractous lens. In The Orular Lens (Ed. Maisel. H.). Pp. 367-404. Marcel Dekker: New York.

Hockwin, 0. (1985). The causes and prevention of cataract blindness. Endenmer. (New Series) 9, 122-35.

Huizinga, A., Bot, A. C. ('.. De Mul, F.. Vrensen, G. F. J. M. and Greve. J. (1989). Local variation in absolute water content of human and rabbit eye lenses measured by Raman microspectroseopy. Exp. Eye Res. 48, 487-496. 
Iriyama. K.. Mizuno. A., Ozaki. Y.. Itoh, K. and Matzuzaki. H. (1982-3). An application of laser Raman spectroscopy to the study of a hereditary cataractous lens; on the Raman band for a diagnostic marker of cataractous signatures. Curr. Eye Res. 2, 489-92.

Itoh. K.. Ozaki. Y.. Mizuno, A. and Iriyama. K. (1983). Structural changes in the lens proteins of hereditary cataracts monitored by Raman spectroscopy. Biochemistry 22. $1773-8$.

Kuck. J. F. F. and Yu. N. T. (197X). Raman and fuorpscent emission of the human lens. A new fluorophore. Exp. Eye Res. 27. 737-41.

Mathies. R. and Yu, N. T. (1978). Raman spectroscopy with intensified Vidicon detectors: a study of intact bovine lens proteins. J. Raman spect. 7. 349-5:2.

Mizuno, A., Ozaki. Y.. Kamada, Y., Mivazaki. H.. Itoh. K. and Iravama, K. (1981-2). Direct measurement of Raman spectra of intart lens in a whole eyeball. Curr. Eye Res. 1. $6199+13$.

Ozaki, Y.. Mizuno, A.. Itoh, K.. Yoshiura, M., Iwamoto. T. and Iriyama, K. (1983). Raman spertroscopic study of age-related structural changes in the lens proteins of an intact mousc lens. Biochemistry 22. 6254-9.

Spector. A. (1984). The search for a solution to senile ("ataracts. Inest. Ophthalmol. Vis. Sri. 25. $130-140$.

Yu. N. T.. Bando, M. and Kuck. .J. F. R. (1985a). Fluorescence/Raman intensity ratio for monitoring the pathologic state of human lens. Invest. Ophthalmol. Vis. Sci. 26. 97-101.

Yu. N. T., De Nagel, D. C. Pruett. P. L. and Kuck. J. F. R. (1985b). Disulfide bond formation in the eye lens. Proc. Natl. Acad. Sci. C.S.A. 82, 7965-8.

Yu. N. T. and East. E. J. (1975). Laser Raman spectroscopic studies of ocular lens and its isolated protein fractions. J. Biol. (hem. 250, 2196-202.

Yu, N. T.. Kuck. J. F. R. and Askren, C. C. (1979). Red fluorescence in older and brunescent lenses. Invest. Ophthalmol. Vis. Sci. 18, 1278-80.

Yu. N. T.. Kuck. J. F. R. and Askren. ( . C. (1981-2). Laser Raman spectroscopy of the lens in situ, measured in an anesthetized rabbit. Curr. Eye Res. 1. 615-18. 